\title{
A meta-analysis of the prevalence of attention deficit hyperactivity disorder in incarcerated populations
}

\author{
S. Young ${ }^{1,2 *}$, D. Moss ${ }^{3}$, O. Sedgwick ${ }^{4}$, M. Fridman ${ }^{5}$ and P. Hodgkins ${ }^{6}$ \\ ${ }^{1}$ Centre for Mental Health, Division of Brain Sciences, Department of Medicine, Imperial College London, UK \\ ${ }^{2}$ Broadmoor Hospital, West London Mental Health Trust, London, UK \\ ${ }^{3}$ Caudex Medical, Oxford, UK \\ ${ }^{4}$ Department of Psychology, Institute of Psychiatry, King's College London, UK \\ ${ }^{5}$ AMF Consulting, Inc., Los Angeles, CA, USA \\ ${ }^{6}$ Global HEOR, Vertex Pharmaceuticals, Boston, MA, USA
}

Background. Studies report the variable prevalence of attention deficit hyperactivity disorder (ADHD) in incarcerated populations. The aim of this meta-analysis was to determine the prevalence of ADHD in these populations.

Method. Primary research studies reporting the prevalence (lifetime/current) of ADHD in incarcerated populations were identified. The meta-analysis used a mixed log-binomial model, including fixed effects for each covariate and a random study effect, to estimate the significance of various risk factors.

Results. Forty-two studies were included in the analysis. ADHD prevalence was higher with screening diagnoses versus diagnostic interview (and with retrospective youth diagnoses versus current diagnoses). Using diagnostic interview data, the estimated prevalence was $25.5 \%$ and there were no significant differences for gender and age. Significant country differences were noted.

Conclusions. Compared with published general population prevalence, there is a fivefold increase in prevalence of ADHD in youth prison populations (30.1\%) and a 10-fold increase in adult prison populations (26.2\%).

Received 2 September 2013; Revised 3 March 2014; Accepted 4 March 2014; First published online 7 April 2014

Key words: ADHD, crime, diagnosis, incarcerated, offender, prevalence, prison.

\section{Introduction}

Attention deficit hyperactivity disorder (ADHD) is defined in DSM-IV (APA, 1994) and ICD-10 (WHO, 1992) as high levels of hyperactive, impulsive and/or inattentive behaviours beginning in early childhood. A level of impairment in at least two areas of life needs to be evident for at least 6 months' duration for a diagnosis of ADHD to be made. ADHD is a common disorder that often persists into adulthood (Faraone et al. 2006), affecting 3-7\% of youths (Asherson, 2004; Asherson et al. 2005; Polanczyk et al. 2007; Willcutt, 2012) and 1-5\% of adults (Asherson, 2004; Asherson et al. 2005, 2012; Kessler et al. 2006; Simon et al. 2009; Willcutt, 2012).

There is no generally accepted estimate of the prevalence of ADHD in incarcerated populations; research studies have consistently reported a disproportionately higher rate of individuals with ADHD in the criminal justice system compared with general population

\footnotetext{
* Address for correspondence: Dr S. Young, Centre for Mental Health, Division of Brain Sciences, Department of Medicine, Imperial College London, 37 Claybrook Road, London W6 8LN, UK.

(Email: susan.young1@imperial.ac.uk)
}

prevalence. These individuals, who are often untreated, seem to have greater judicial contact and pose higher risk within the criminal justice system. Compared with other offenders, they present with younger age at first contact, greater recidivism and institutional behaviour disturbance (Young et al. 2003, $2009 b$, 2011). A Scottish prison study found that inmates with ADHD symptoms were involved in up to eight times more institutional aggression; this strong association was maintained even when controlling for antisocial personality characteristics, with aggressive incidents being six times greater compared with non-ADHD peers (Young et al. 2009b). These problems are likely to be associated with underlying deficits in executive dysfunction (Young et al. 2007; Bramham et al. 2009; Rose et al. 2009); in particular, behavioural disinhibition and emotional dysregulation (Gudjonsson et al. 2009, 2012).

However, prevalence varies widely among studies and methodologies differ. Hence, this study reviewed the data obtained from a systematic literature search performed to ascertain the lifetime/current prevalence of ADHD in prison populations in both youths and adults. The study aimed to specify (1) the prevalence of ADHD in incarcerated youth and adult offenders, 
including differences by gender; (2) prevalence from studies applying screening tools and diagnostic clinical interviews; (3) differences in prevalence obtained from retrospective diagnoses from adults and youth prevalence obtained using a current diagnoses methodology; and (4) geographical differences.

\section{Method}

\section{Eligibility criteria}

The systematic review was performed in accordance with the Preferred Reporting Items for Systematic reviews and Meta-Analyses (PRISMA; Liberati et al. 2009) guidelines. Initial searches were carried out in a variety of databases and websites to gain an understanding of the amount of information available. Reports published since 1980 and in English were included.

\section{Data sources}

Searches were conducted in OvidSP Medline (1948 to present) and EMBASE (1988 to present segment), Datastar PsycINFO (unrestricted) and Social SciSearch (1972 to date; limited to English and added since 1 January 1980), including the literature published between 1 January 1980 and 3 May 2011; a citations update was performed on 21 June 2011 and extended to 31 August 2012 in October 2012.

\section{Search}

Search terms were developed, refined and tested for relevance by cross-checking results against a list of known relevant articles provided by the lead author. The following descriptors were used in OvidSP EMBASE (1988 to present segment): ADHD; attention deficit disorder; [EMTREE] crime; criminals; criminology; criminal behaviour; criminal justice; criminal law; court; criminal psychology; delinquency; juvenile delinquency; gang; legal evidence; legal procedure; police; legal liability; mandatory programs; violence; prisons; prisoner; probation; law enforcement; recidivism; jurisprudence; punishment; offender; drug abuse; drug misuse.

\section{Study selection}

Articles obtained from the final searches were first de-duplicated, then an inclusion/exclusion process was undertaken based on the following exclusion criteria: non-English language articles, articles published before 1980, animal studies, articles that were not peer reviewed (e.g. theses), and articles that obviously did not hold relevance (e.g. they did not focus on ADHD or crime, or they focused on substance misuse but not from the criminology perspective). Review articles pre-2006 were excluded, and post-2006 reviews were kept with the sole purpose to examine bibliographies to check for any other articles not identified in the search; these review articles were not included in the final prevalence calculation; only primary research articles were included. Articles with no abstract (including initial PsycINFO and Social SciSearch search outputs) were also excluded unless the title or other information (e.g. key terms) suggested they may hold relevance. The inclusion/exclusion review was first completed based on title/abstract/key words by four researchers, and if the relevance of an article was unclear, the full text was retrieved before a final decision was made. Once the initial bulk of the inclusion/exclusion process was completed, abstracts were reviewed independently by the lead author before full-text articles were retrieved. Any uncertainties over including/excluding articles were discussed among the researchers and a final decision was made once the full-text articles were reviewed.

The full texts of included articles were retrieved for detailed evaluation against eligibility criteria. Only the publications that focused on incarcerated/prison populations and those that reported ADHD prevalence were selected. Studies that reported results on mixed gender populations were excluded as we aimed to separate the gender effect in modelling.

\section{Data collection process}

A data extraction sheet was developed in Microsoft Excel and pilot tested on 13 randomly selected studies and refined accordingly. The publications were divided among four researchers (including two authors: D.M. and O.S.) who performed the data extraction independently. Data were reviewed for consistency and any queries were resolved by discussion among the researchers and the lead author. The lead author also made the final decision whether to include/exclude data by reviewing the identified publications.

The authors of 11 studies were contacted directly in personal communications to ascertain missing information relating to age of the study population (Black et al. 2004; Sanz-Garcia et al. 2010a,b), gender (Vitelli, 1996), method of assessment of ADHD (Gordon \& Moore, 2005), study population (Cahill et al. 2012; Colins et al. 2012) and verification of the incarcerated status of the sample (Langevin, 2003; Rosler et al. 2009; Retz \& Rosler, 2010; Lindsay et al. 2012). All responded with additional information that had not been included in the original publication and, if meeting inclusion criteria, was included in this meta-analysis (indicated in Supplementary Tables S1 and S2). 
Some cohorts of prison populations were published more than once. To avoid double counting data, multiple reports of the same cohort were pieced together by juxtaposing author names, treatment comparisons, sample sizes and outcomes. An exception to this rule occurred in relation to the Young et al. (2010a, 2011) reports; whereas Young et al. (2010a) used diagnostic interviews, Young et al. (2011) used screening data to provide ADHD prevalence. In the interest of obtaining meaningful data on diagnostic differences in ADHD, these reports were considered as separate studies. In addition, following author communication, more recent data from Cahill et al. (2012) were included rather than data from an earlier publication of the same population (Coolidge et al. 2009).

\section{Data items}

For each included study, data were extracted into a data set containing: (1) study location (country of origin), (2) study sample size, (3) study population (including age and gender), (4) diagnostic criteria (screening or diagnostic interview), (5) study design (retrospective, that is adult studies reporting a prevalence of childhood ADHD, or current diagnoses), (6) ADHD prevalence and (7) treatment (including prison management). We have used the term 'prison' but included all individuals who were incarcerated, jailed or imprisoned, or similar descriptors. For the analysis, studies were grouped by age for youth and adult offenders (see Supplementary Tables S1 and S2). It was noted that there was no clear definition across publications on the age of an adult versus a youth. For the purposes of this meta-analysis, we designated 18 years to be the cut-off point for a youth becoming an adult (i.e. youths were $\leqslant 18$ years and adults were $>18$ years); papers reporting youth data often cited 18 years as the upper limit of the age range of participants. In those papers where an age range was given that spanned this cut-off point (e.g. 15-28 years), the mean (or median if mean was not provided) was used to define whether the study population should be listed as 'youth' or 'adult'. For studies reporting on (1) both genders separately, (2) both diagnostic criteria or (3) both study designs, information was recorded as two separate observations ('study strata') linked by the study number. None of the studies reported separate results on more than one of these three characteristics and none reported on both age groups.

For a diagnosis of ADHD to be given in adulthood, clinically significant symptoms must have been present in childhood. Therefore, when assessing adults for $\mathrm{ADHD}$, it is necessary to establish whether they meet criteria for childhood ADHD, requiring them to retrospectively report on their symptoms (if a diagnosis did not already exist). Some adult studies $(n=13)$ included in this meta-analysis also reported a prevalence of childhood ADHD for the cohort (referred to as a retrospective diagnosis in this study).

\section{Quality control}

To ascertain the validity of eligible publications, each researcher checked and independently reviewed a random sample of each others' papers for data extraction and interpretation consistency. Disagreements were resolved by reviewing the data source and by discussion between the three reviewers (one of whom is an author).

\section{Statistical methods}

Summary prevalence estimates were calculated for the meta-analysis. Observed prevalence per study stratum was reported by age and gender groups. Modelpredicted prevalence was reported by the various model covariates together with their corresponding 95\% confidence intervals (CIs).

A mixed log-binomial model was fitted for the observed prevalence in the study strata to estimate the significance of the various risk factors (model 1). Covariates collected for predicting ADHD prevalence included gender, age group, diagnostic method, study design and country. The model included fixed effects for each of the covariates and a random study effect, and can be defined as follows:

$$
\begin{aligned}
& y_{i j} \sim \operatorname{binomial}\left(n_{i j}, p_{i j}\right) \\
& \begin{aligned}
\log \left(p_{i j}\right)= & \operatorname{study}_{i}+\operatorname{gender}_{i j}+\operatorname{age}_{i j}+\text { diagnostic method }_{i j} \\
& +\operatorname{study}_{\text {design }}+\text { country }_{i},
\end{aligned}
\end{aligned}
$$

where $y_{i j}$ is the number of patients with the response, $p_{i j}$ is the ADHD prevalence and $n_{i j}$ is the total number of inmates included in study $i$ and on stratum $j$. As implemented here, the model made the following assumptions:

(1) study $_{i}$ represented a random study effect, assumed to follow a normal $\left(0, \sigma^{2}\right)$ distribution. The study effect was considered to be the within-study logarithmic baseline prevalence, thus eliminating the study-specific effect from the other comparison estimates.

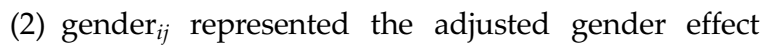
common to all patients in study $i$ and stratum $j$ on the logarithm of prevalence. Similarly for age $\mathrm{e}_{i j}$ diagnostic method $_{i j}$, study design $i j$ and country ${ }_{i}$. Countries were also grouped into regions in 
an attempt to obtain more stable estimates (North America, Europe and Other).

Given the observed level of interaction between gender, age group and diagnostic method, these three covariates were fully interacted in the model and were represented by eight indicator variables (one omitted as a reference group). Other interactions were also tested for significance. Marginal estimates of prevalence (least-square means) for each of the covariates (e.g. males, adults, etc.) and for their combinations were calculated by applying the inverse logarithmic transformation to model predictors. To estimate the sensitivity of results to the diagnostic method, the model was refitted to a subset of data using diagnostic interview strata only (model 2). For the sensitivity analysis model (model 2), the aforementioned eight indicator variables for the interaction of gender, age group and diagnostic method were collapsed to four to capture the interaction of age-by-gender group.

The models were fitted adopting a frequentist estimation approach using PROC GLIMMIX in SAS version 9.2 (SAS Institute, USA).

\section{Results}

In total, 8520 publications were identified following the OvidSP Medline, EMBASE, Datastar, PsycINFO and Social SciSearch database search. Publications not specifically relating to ADHD and criminality and duplicates between databases were excluded electronically, leaving 325. Once further duplicates had been identified manually, 311 publications remained. A further 218 publications were excluded after further review as they did not report on samples composed entirely of incarcerated/prison populations. Of the 93 articles remaining, a further 40 articles were excluded as they did not provide prevalence data on ADHD; 53 publications included ADHD prevalence data. Three studies (Young et al. 2009a; Ginsberg \& Lindefors, 2012; Tidefors \& Strand, 2012) were excluded as they used samples composed solely of participants who had ADHD, hence giving a prevalence rate of $100 \%$. A further eight studies were excluded as they only provided mixed-gender prevalence (Milin et al. 1991; Fulwiler et al. 1997; Rasmussen et al. 2000, 2001; Black et al. 2004, 2010; Anckarsater et al. 2007; Einat \& Einat, 2008; Gudjonsson et al. 2009), leaving 42 studies included in the meta-analysis, reporting prevalence by gender (Fig. 1).

\section{Prevalence}

Observed ADHD prevalence per study stratum by age group (youths $\leqslant 18$ years and adults $>18$ years) and gender showing all data (42 studies, 61 strata) and interview diagnosis strata (21 studies, 30 strata) are presented in Fig. 2. Bubble plots show the ADHD prevalence per study stratum for the full sample and the subset of study strata where a diagnostic interview was administered. The plots demonstrate that some of the high prevalence outliers are study strata where screening was used for ADHD diagnosis. Thus, all other data used diagnostic data only. No other differences were observed between the gender and age groups. Table 1 and Figs 3 and 4 (and Supplementary Figs S1 and S2) summarize the results obtained from model 1 (all data, that is both screening and diagnostic interview) and model 2 (diagnostic interview subset only). There were no significant differences between genders in both models.

Overall, the observed ADHD prevalence in prison populations in all 42 studies (61 study strata) was $21.3 \%$ (total number of inmates was 26641, of whom 5677 were reported to be diagnosed with ADHD). The observed ADHD prevalence in prison populations for inmates with an interview diagnosis (21 studies, 30 study strata) was $20.5 \%$ (total number of inmates was 19575, of whom 4008 were reported to be diagnosed with ADHD).

Screening versus diagnostic clinical interview methodology

Studies using screening for diagnosis had a significantly higher estimated ADHD prevalence of $43.3 \%$ (95\% CI 33.2-56.4) compared with $25.5 \%$ (95\% CI 20.0-32.4) obtained from the subset of studies using a diagnostic clinical interview $(p=0.001)$. This suggested a high rate of false positives was being identified by screening tools, and thus subsequent reported analysis used prevalence obtained only from diagnostic clinical interview data (i.e. model 2).

\section{Retrospective versus current youth diagnoses methodology}

ADHD prevalence was estimated to be significantly lower $(p<0.001)$ in studies with current diagnoses; ADHD prevalence for current diagnoses was $21.7 \%$ (95\% CI 17.5-26.9), compared with $36.4 \%$ (95\% CI 25.6-51.8) for retrospective diagnoses.

\section{Geographical differences}

There were significant differences in ADHD prevalence estimated across countries $(p<0.0001)$. ADHD prevalence ranged from $6.6 \%$ in Brazil (Ponde et al. 2011) to $65.2 \%$ in Sweden (Table 1 and Fig. 2; model 2 diagnostic interview). When aggregated into three regions (North America, Europe and Other countries), differences were not significant when fitting models similar to model 2, replacing countries with 


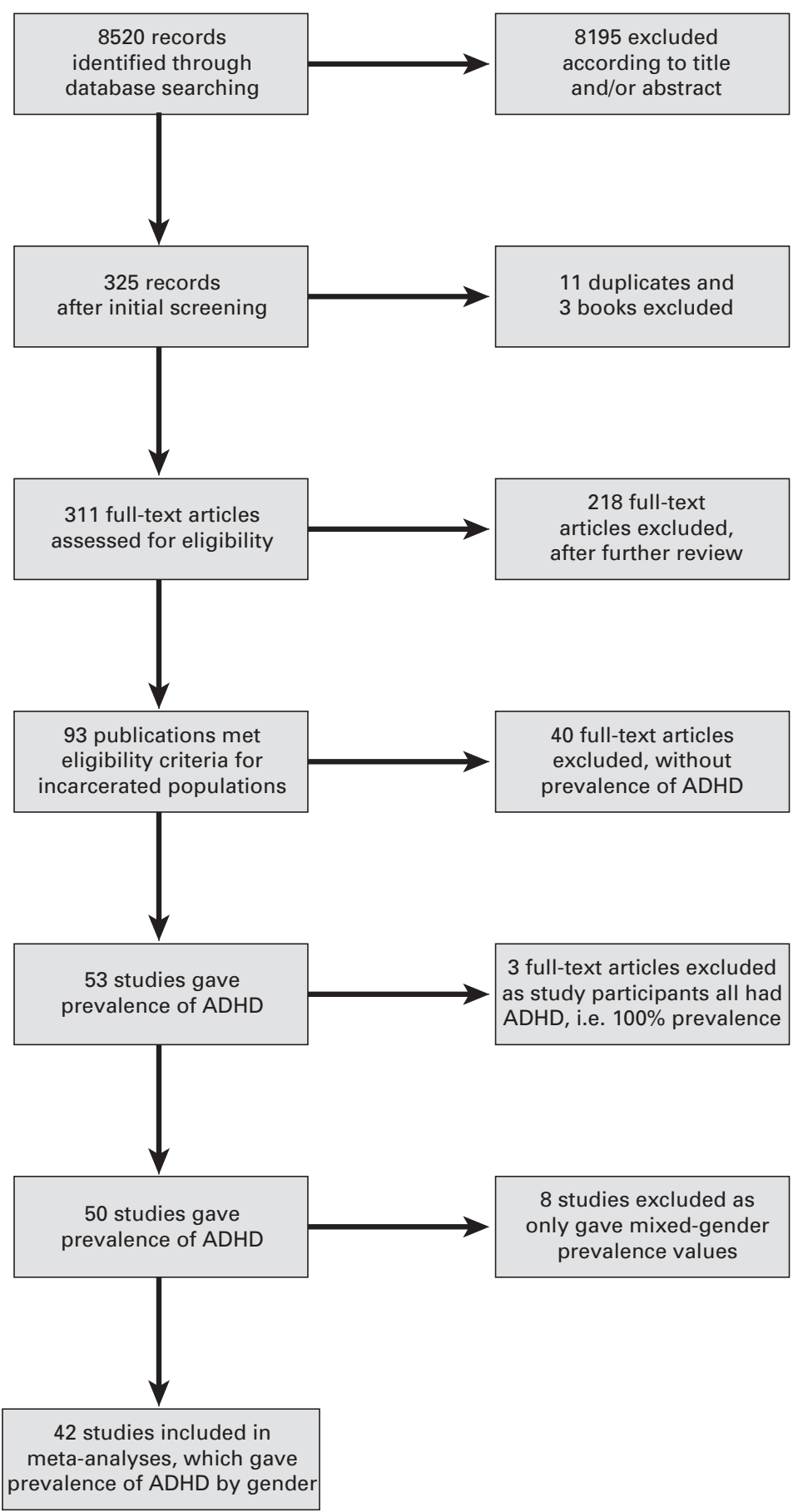

Fig. 1. Flow diagram of the manual screening process for eligible literature inclusion. ADHD, attention deficit hyperactivity disorder.

regions $(p=0.240)$; Europe had the highest estimated prevalence $(32.1 \%)$, followed by North America $(26.9 \%)$ and Other countries $(17.6 \%)$.

Males versus females

Prevalence estimates for males with ADHD were not significantly different from estimates for females with
ADHD: $30.3 \%$ (95\% CI 23.9-38.4) versus $26.1 \%$ (95\% CI 19.3-35.2).

Youths versus adults

Youth prevalence estimates were not significantly different from estimates for adults: $30.1 \%$ (95\% CI $22.1-$ 41.1) versus $26.2 \%$ (95\% CI 18.4-37.5). 


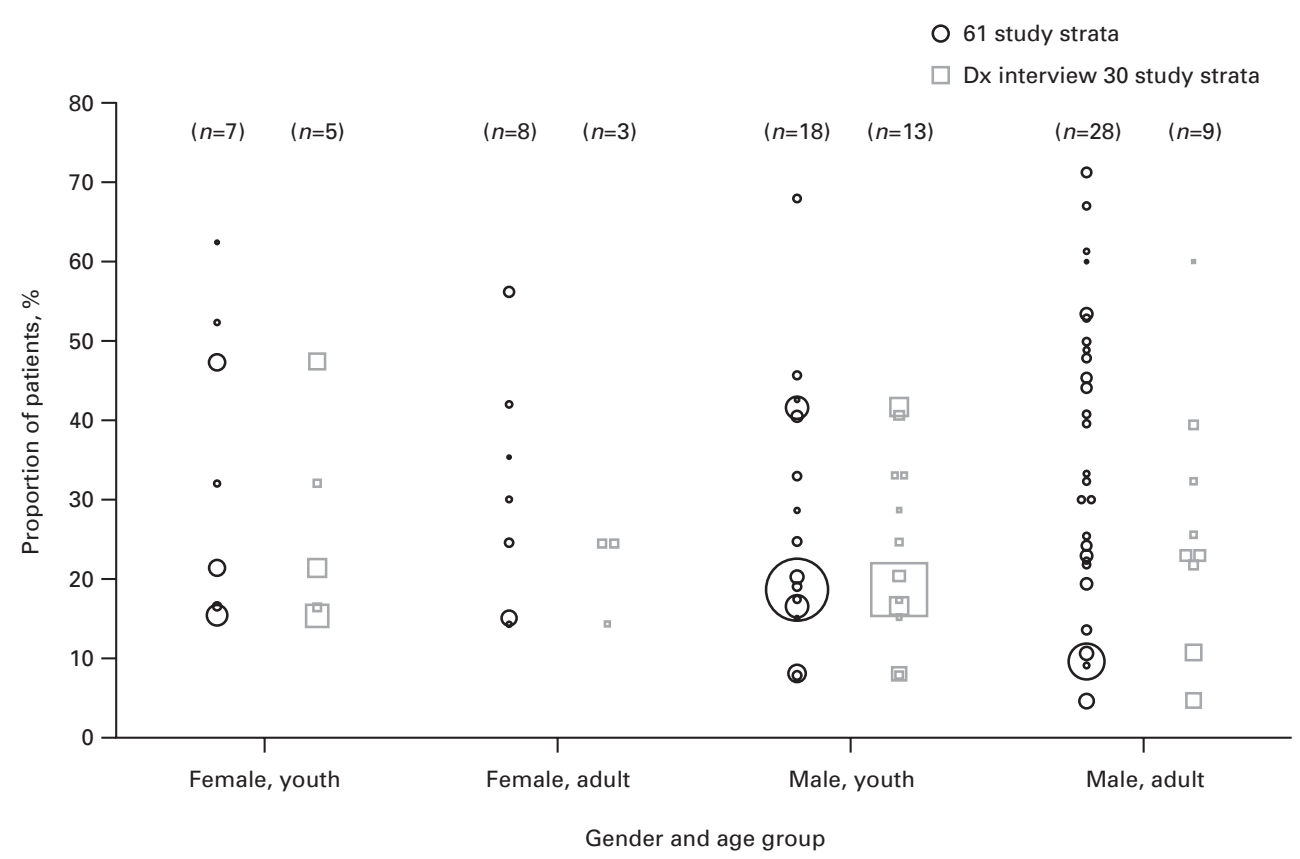

Fig. 2. Observed attention deficit hyperactivity disorder prevalence per study stratum by age group (youths $\leqslant 18$ years and adults $>18$ years) and gender showing all data (42 studies, 61 strata) and interview diagnosis (Dx) strata (21 studies, 30 strata). Each bubble/square in the plot represents a study stratum. Bubble/square areas are proportional to stratum sample size. The numbers of study strata per column are shown in parentheses.

\section{Gender-by-age interaction}

Gender-by-age (Table 1 and Fig. 4) comparisons reported that female adults had the lowest predicted ADHD prevalence: $22.1 \%$ (95\% CI 13.6-35.8). By contrast, the prevalence estimate for male adults was $31.2 \%$ (95\% CI 22.7-42.9). Female and male youth estimates were $30.8 \%$ (95\% CI 22.4-42.2) and $29.5 \%$ (95\% CI 21.6-40.1), respectively.

There were no significant differences found within the clinical interview diagnostic groups among the four gender-by-age groups.

\section{Discussion}

\section{Prevalence}

This review presents a meta-analysis of 42 studies conducted in 15 countries that provides a reliable estimate of $25.5 \%$ as the prevalence of ADHD in incarcerated populations from studies using diagnostic clinical interview. Heterogeneity is likely to be present in most meta-analyses as individual studies with the 'same' population and study characteristics are never identical with respect to both measured and unmeasured factors, which can lead to differences in outcome. For this reason, models that allow for heterogeneity are recommended (DerSimonian \& Laird, 1986; van Houwelingen et al. 2002). We fitted models that assumed a fixed effect (equal across studies) of measurable covariates, such as gender or age group, on ADHD prevalence and a random effect for study that allowed for the same types of subjects (e.g. male adult with a diagnostic interview and current diagnoses design) to have different prevalence in different studies, and also provided for a mechanism to allow prevalence correlation in the same study strata (intracluster correlation).

In recent years, a high prevalence of psychopathology (depression, psychotic illness, ADHD, conduct disorder) has been recognized in prison inmates (Fazel et al. 2008a, b; Bradley, 2009), and although more comprehensive mental health screens are being developed for use at prison reception to develop effective care strategies (Senior et al. 2012), a possible explanation for the results of the meta-analysis may be that there is a high rate of false positives identified by ADHD screens in youths/adults compared with the diagnostic interview-only subset. Retrospective screening and interview accounts of childhood symptoms given by adult inmates were estimated to be significantly higher than those given by a current diagnoses cohort $(36.4 \%$ v. $21.7 \%$ ). It seems important that all inmates are considered for mental health screening, including ADHD, and those with positive screens be referred for a clinical assessment. What is unknown, however, is the rate of false-negative screens in this population.

The predominantly reported analysis used prevalence obtained only from diagnostic clinical interview 
Table 1. Summary of prevalence results (\%) from fitted models (youths $\leqslant 18$ years and adults $>18$ years)

\begin{tabular}{|c|c|c|}
\hline Covariate & $\begin{array}{l}\text { Model 1: } \\
\text { All data }\end{array}$ & $\begin{array}{l}\text { Model 2: Diagnostic } \\
\text { interview subset }\end{array}$ \\
\hline \multicolumn{3}{|l|}{ Gender $\times$ Age group $\times$ Diagnostic method } \\
\hline F, Adult, Interview $(n=3)$ & 17.8 & N.A. \\
\hline F, Adult, Screen $(n=5)$ & 37.8 & \\
\hline F, Child/Adolescent, Interview $(n=5)$ & 31.3 & \\
\hline F, Child/Adolescent, Screen $(n=2)$ & 66.5 & \\
\hline M, Adult, Interview $(n=9)$ & 25.3 & \\
\hline M, Adult, Screen $(n=19)$ & 30.7 & \\
\hline M, Child/Adolescent, Interview $(n=13)$ & 30.0 & \\
\hline M, Child/Adolescent, Screen $(n=5)$ & 45.6 & \\
\hline$p$ value & 0.006 & \\
\hline \multicolumn{3}{|l|}{ Gender $\times$ Age group } \\
\hline F, Adult $(n=3)$ & N.A. & 22.1 \\
\hline F, Child/Adolescent $(n=5)$ & & 30.8 \\
\hline M, Adult $(n=9)$ & & 31.2 \\
\hline M, Child/Adolescent $(n=13)$ & & 29.5 \\
\hline$p$ value & & 0.242 \\
\hline \multicolumn{3}{|l|}{ Study design $\left(n_{1}=61, n_{2}=30\right)$} \\
\hline Current diagnoses & 23.4 & 21.7 \\
\hline Retrospective child diagnoses & 47.1 & 36.4 \\
\hline$p$ value & $<0.0001$ & $<0.001$ \\
\hline \multicolumn{3}{|l|}{ Country $^{\mathrm{a}}$} \\
\hline Austria $\left(n_{1}=2, n_{2}=2\right)$ & 60.7 & 47.8 \\
\hline Brazil $\left(n_{1}=2, n_{2}=2\right)$ & 9.4 & 6.6 \\
\hline Canada $\left(n_{1}=1, n_{2}=0\right)$ & 49.1 & \\
\hline Germany $\left(n_{1}=5, n_{2}=2\right)$ & 49.3 & 31.4 \\
\hline Greece $\left(n_{1}=1, n_{2}=0\right)$ & 45.6 & \\
\hline Iceland $\left(n_{1}=4, n_{2}=0\right)$ & 39.2 & \\
\hline $\operatorname{Iran}\left(n_{1}=1, n_{2}=1\right)$ & 51.0 & 40.1 \\
\hline Ireland $\left(n_{1}=1, n_{2}=0\right)$ & 13.4 & \\
\hline South Korea $\left(n_{1}=2, n_{2}=0\right)$ & 35.5 & \\
\hline Netherlands $\left(n_{1}=2, n_{2}=2\right)$ & 18.0 & 14.2 \\
\hline Nigeria $\left(n_{1}=1, n_{2}=1\right)$ & 22.8 & 18.1 \\
\hline Spain $\left(n_{1}=3, n_{2}=1\right)$ & 50.4 & 45.5 \\
\hline Sweden $\left(n_{1}=8, n_{2}=1\right)$ & 50.1 & 65.2 \\
\hline $\mathrm{UK}\left(n_{1}=4, n_{2}=1\right)$ & 31.4 & 39.4 \\
\hline USA $\left(n_{1}=24, n_{2}=17\right)$ & 33.8 & 25.7 \\
\hline$p$ value & $<0.002$ & $<0.0001$ \\
\hline
\end{tabular}

F, Female; M, male; N.A., not applicable.

${ }^{a}$ The number of study strata included are listed in parentheses for each covariate (number of strata in models 1 and 2 are provided for covariates in both models, respectively). The numbers of studies in each country are: Austria $(n=1)$, Brazil $(n=1)$, Canada $(n=1)$, Germany $(n=3)$, Greece $(n=1)$, Iceland $(n=2)$, Iran $(n=1)$, Ireland $(n=1)$, South Korea $(n=1)$, Netherlands $(n=2)$, Nigeria $(n=1)$, Spain $(n=2)$, Sweden $(n=6)$, UK $(n=3)$, USA $(n=16)$. All studies are listed in Supplementary Tables S1 and S2.

data. This is also consistent with the diagnosis of ADHD in the community and enables a fairer comparison when comparing rates with the general population.
Consistent with prevalence and patterns of remission in the general population (Polanczyk et al. 2007; Young \& Gudjonsson, 2008; Simon et al. 2009), we would expect adult prevalence to have been 


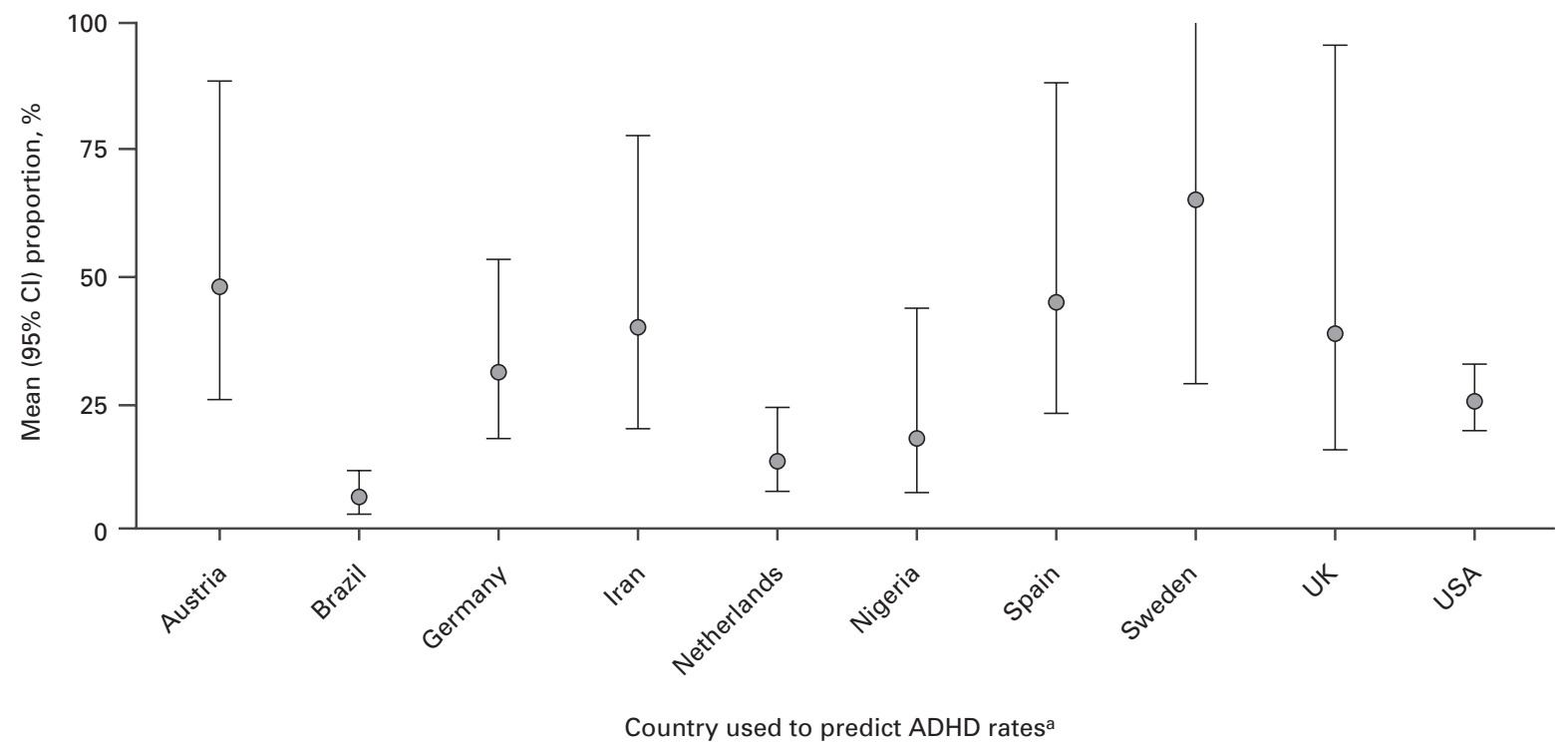

Fig. 3. Model-predicted attention deficit hyperactivity disorder (ADHD) prevalence by country (model 2: diagnostic interview only). ${ }^{\text {a }}$ Upper bounds of $95 \%$ confidence intervals (CIs) are truncated to 1.0 .

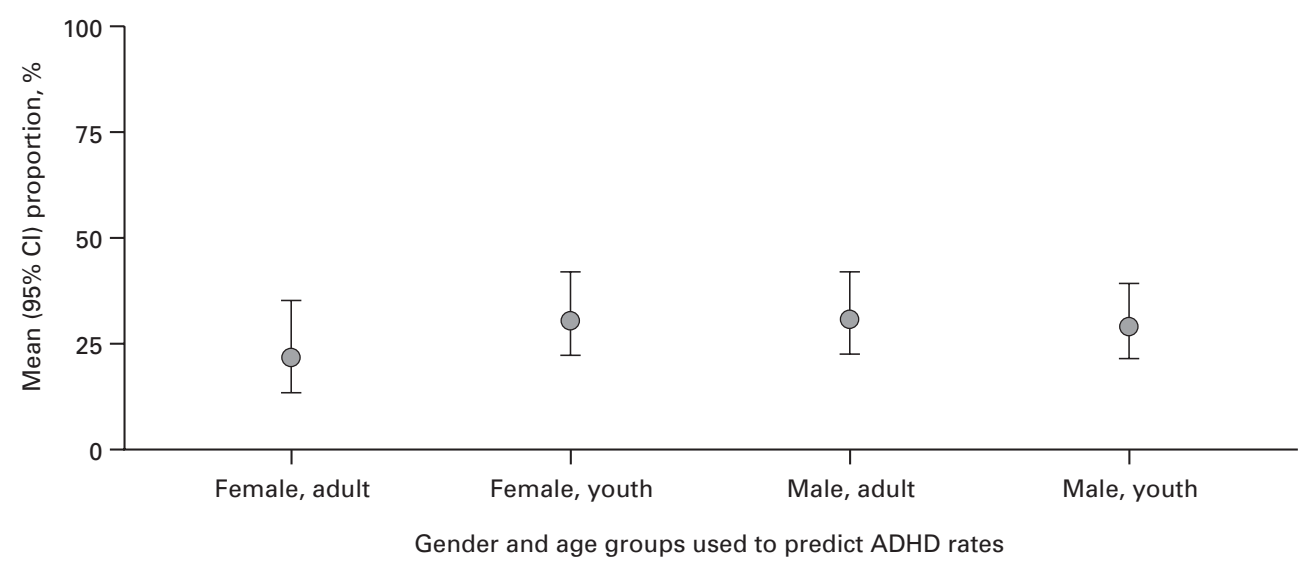

Fig. 4. Model-predicted attention deficit hyperactivity disorder (ADHD) prevalence by gender group and age groups (youths $\leqslant 18$ years and adults $>18$ years; model 2: diagnostic interview only). CI, Confidence interval.

lower than youth prevalence; yet when applying a diagnostic interview (model 2), these were very similar $(26.2 \%$ v. 30.1\%). It has been reported that the onset of offending is at a younger age for youth with $\mathrm{ADHD}$, even as young as 10 years of age (Langley et al. 2010; Young et al. 2010b), and perhaps these young offenders are less likely to be given a custodial sentence and/or are diverted out of the criminal justice system (e.g. to residential homes as 'at-risk' youths). However, an arbitrary classification was determined in the current review to stratify youth and adult offenders (i.e. if the mean/median age was above 18 years, a study was classified as an 'adult study'). This might have led to some youth diagnoses being included as an adult diagnosis, and possibly skewed the data.

\section{Geographical differences}

Large differences were reported between countries. However, when grouped into three regions (North America, Europe and Other countries), these differences were not significant. Europe had the highest estimated rate, followed by North America and then Other countries. These variations may be due partly to study sample sizes: $70 \%$ (seven of 10 ) of the diagnostic interview studies carried out in North America had sample sizes $>200$, compared with only 22\% (two of nine) of European studies. The North American prevalence $(26.9 \%)$ is closer to the prevalence obtained overall (by diagnostic interview) for offenders with youth and adult $\operatorname{ADHD}(30.1 \%$ and $26.2 \%$, respectively). Hence, these 
larger samples may give an accurate estimate of prevalence.

The differential may also reflect differences in the North American and European criminal justice systems. Following the introduction of tougher laws and penalties surrounding drug crimes by the US government, the number of inmates convicted of a drug crime rose by $1300 \%$ in the USA between 1980 and 2001 (Jensen et al. 2004). This compares with only $12 \%$ of a Scottish prison population incarcerated for drug-related crimes (Young et al. 2010b). Nevertheless, just under half of this Scottish sample self-reported drug dependence, and hierarchical multiple regressions indicated that previous drug use was the most powerful predictor of the total extent of offending, whereas a history of ADHD symptoms was the most powerful predictor of violent crimes. Thus, US prison populations may have an over-representation of those who have been incarcerated for drug crimes, which may not necessarily be related to 'reactive, impulsive offences' (e.g. robbery and property crimes) thought to be associated with ADHD (Retz \& Rosler, 2009).

\section{Gender differences}

Female adults (with diagnostic interview) had the lowest predicted ADHD prevalence when comparing by age and gender $(22.1 \%$ v. $31.2 \%$, male adults $)$. However, female youths had similar prevalence to male youths (30.8\% and $29.5 \%$, respectively). The general population prevalence indicates a $4: 1$ ratio of boys to girls with ADHD (Cuffe et al. 2005), yet in the prison population this ratio seems much reduced. Hence, the protective mechanisms that may usually keep females out of prison (e.g. sentencing policies, family considerations) seem to be overridden for female offenders with ADHD. However, only a few data sets reporting on female prevalence were included in the 'diagnostic interview' analysis $(n=8)$ compared with male prevalence $(n=22)$, which may have given a restricted representation of the position. A recent study from Konstenius et al. (2012) sampled 56 adult incarcerated women who were assessed by diagnostic interview in a Swedish prison, and reported that $29 \%$ met DSM-IV criteria for ADHD. This study, not identified during our initial literature search, supports a similar ADHD prevalence in female adults to this metaanalysis. In the present review, male adult diagnostic interview data are the most reliable because of the quantity and hence high power available: 14752 male youth interview subjects and 1978 male adult interview subjects compared with 2623 female youth and 222 female adult subjects.

The prevalence rate of males to females in adults with ADHD ( 1.5:1) is much lower than the observed ratio of 4:1 in youths with ADHD (Montejano et al. 2011; Willcutt, 2012; McCarthy et al. 2012). Male adults diagnosed by clinical interview showed a similar prevalence to youths (31.2\% v. 30.8\% female or $29.5 \%$ male). This suggests that incarcerated youths may remain in the criminal justice system because of repeat offending. Analysis of data from the Swedish National Register found that $36.6 \%$ males with ADHD were convicted of crime compared with $15.4 \%$ of females. Importantly, it was found that the use of ADHD medication reduced the risk of criminality among probands with ADHD: by $32 \%$ in men and $41 \%$ in women (Lichtenstein et al. 2012).

\section{Limitations}

Two important caveats to this review should be noted. First, publication bias is always an issue in systematic reviews, but efforts to address this were made in several ways. Data were obtained from all available sources, including those from electronic databases and authors, and review papers were checked (post-2006). Bias in study selection was addressed by delivering training on how to extract data from a random sample of publications, and each researcher checked and independently reviewed a random sample of each others papers for data interpretation consistency. Second, factors such as the reliability of ADHD diagnoses and differences in the criminal justice system between and within countries could have contributed to the broad ranges of prevalence observed in this review. The heterogeneity of samples used is also a potential source of variability and was the reason for using a fitted model that assumed a fixed effect (equal across studies) of measurable covariates but random study effects in the meta-analysis. In addition, only those publications since 1980 and in English were included.

\section{Conclusions}

Overall, the estimated prevalence of ADHD in incarcerated populations is $25.5 \%$ based on diagnostic clinical interviews. The ADHD prevalence was estimated to be significantly lower in studies with current diagnoses compared with retrospective diagnoses. There was a large variation in ADHD prevalence between countries, but this was no longer evident when grouped regionally. This systematic review and meta-analysis found, on average, a fivefold increased prevalence of ADHD in youth prison populations (30.1\%) and a 10 -fold increase in adult prison populations (26.2\%) compared with published general population prevalence $(3-7 \%$ and $1-5 \%$, respectively). Female adults had a lower prevalence of ADHD, when compared by age and gender, than male adults. However, the risk for females was almost as high as that for males. 


\section{Supplementary material}

For supplementary material accompanying this paper visit http://dx.doi.org/10.1017/S0033291714000762.

\section{Acknowledgements}

We thank E. Watts (Fishawack Communications Ltd, UK, funded by Shire AG, Switzerland) for performing the initial searches; G. Stoudt (Shire, USA) for performing the database literature searches; and J. Wright and K. Lay (Caudex Medical, UK, funded by Shire AG, Switzerland) for extracting relevant data from the studies. Editorial assistance in formatting, proofreading, copy-editing and fact-checking was also provided by Caudex Medical, funded by Shire AG, Switzerland. We also thank A. Elsner (Shire AG, Switzerland) for constructive review.

\section{Declaration of Interest}

S. Young has received speakers' fees and travel honoraria from Janssen, Eli Lilly, Shire, Novartis and Flynn Pharma, and received research grants from Janssen, Eli Lilly and Shire. D. Moss is a professional medical writer employed by Caudex Medical, UK, whose contribution to this manuscript was funded by Shire AG, Switzerland. O. Sedgwick has no conflicts of interest to disclose. However, she receives funding support from the National Institute for Health Research (NIHR) Mental Health Biomedical Research Centre at South London and Maudsley National Health Service (NHS) Foundation Trust and King's College London. The views expressed are those of the author(s) and not necessarily those of the NHS, the NIHR or the Department of Health. M. Fridman is a paid statistical consultant to Shire. P. Hodgkins was an employee of Shire and owns stock/stock options in the company. $\mathrm{He}$ is now Vice President, Global HEOR, Vertex Pharmaceuticals, USA. Shire develops and markets drugs to treat psychiatric disorders, including ADHD.

\section{References}

Anckarsater H, Nilsson T, Stahlberg O, Gustafson M, Saury JM, Rastam M, Gillberg C (2007). Prevalences and configurations of mental disorders among institutionalized adolescents. Developmental Neurorehabilitation 10, 57-65.

APA (1994). Diagnostic and Statistical Manual of Mental Disorders, Fourth Edition. DSM-IV. American Psychiatric Association: Washington, DC.

Asherson P (2004). Attention-deficit hyperactivity disorder in the post-genomic era. European Child and Adolescent Psychiatry 13 (Suppl. 1), I50-I70.
Asherson P, Akehurst R, Kooij JJ, Huss M, Beusterien K, Sasane R, Gholizadeh S, Hodgkins P (2012). Under diagnosis of adult ADHD: cultural influences and societal burden. Journal of Attention Disorders 16, 20S-38S.

Asherson P, Kuntsi J, Taylor E (2005). Unravelling the complexity of attention-deficit hyperactivity disorder: a behavioural genomic approach. British Journal of Psychiatry 187, 103-105.

Black DW, Arndt S, Hale N, Rogerson R (2004). Use of the Mini International Neuropsychiatric Interview (MINI) as a screening tool in prisons: results of a preliminary study. Journal of the American Academy of Psychiatry and Law 32, 158-162.

Black DW, Gunter T, Loveless P, Allen J, Sieleni B (2010). Antisocial personality disorder in incarcerated offenders: psychiatric comorbidity and quality of life. Annals of Clinical Psychiatry 22, 113-120.

Bradley K (2009). The Bradley Report. Lord Bradley's review of people with mental health problems or learning disabilities in the criminal justice system. Department of Health: London.

Bramham J, Ambery F, Young S, Morris R, Russell A, Xenitidis K, Asherson P, Murphy D (2009). Executive functioning differences between adults with attention deficit hyperactivity disorder and autistic spectrum disorder in initiation, planning and strategy formation. Autism 13, 245-264.

Cahill BS, Coolidge FL, Segal DL, Klebe KJ, Marle PD, Overmann KA (2012). Prevalence of ADHD and its subtypes in male and female adult prison inmates. Behavioral Sciences and the Law 30, 154-166.

Colins O, Vermeiren R, Vahl P, Markus M, Broekaert E, Doreleijers T (2012). Parent-reported attention-deficit hyperactivity disorder and subtypes of conduct disorder as risk factor of recidivism in detained male adolescents. European Psychiatry 27, 329-334.

Coolidge FL, Segal DL, Klebe KJ, Cahill BS, Whitcomb JM (2009). Psychometric properties of the Coolidge Correctional Inventory in a sample of 3,962 prison inmates. Behavioral Sciences and the Law 27, 713-726.

Cuffe SP, Moore CG, McKeown RE (2005). Prevalence and correlates of ADHD symptoms in the National Health Interview Survey. Journal of Attention Disorders 9, 392-401.

DerSimonian R, Laird N (1986). Meta-analysis in clinical trials. Controlled Clinical Trials 7, 177-188.

Einat T, Einat A (2008). Learning disabilities and delinquency: a study of Israeli prison inmates. International Journal of Offender Therapy and Comparative Criminology 52, 416-434.

Faraone SV, Biederman J, Mick E (2006). The age-dependent decline of attention deficit hyperactivity disorder: a meta-analysis of follow-up studies. Psychological Medicine 36, 159-165.

Fazel M, Langstrom N, Grann M, Fazel S (2008a). Psychopathology in adolescent and young adult criminal offenders (15-21 years) in Sweden. Social Psychiatry and Psychiatric Epidemiology 43, 319-324.

Fazel S, Doll H, Langstrom N (2008b). Mental disorders among adolescents in juvenile detention and correctional facilities: a systematic review and metaregression analysis 
of 25 surveys. Journal of the American Academy of Child and Adolescent Psychiatry 47, 1010-1019.

Fulwiler C, Forbes C, Santangelo SL, Folstein M (1997). Self-mutilation and suicide attempt: distinguishing features in prisoners. Journal of the American Academy of Psychiatry and Law 25, 69-77.

Ginsberg Y, Lindefors N (2012). Methylphenidate treatment of adult male prison inmates with attention-deficit hyperactivity disorder: randomised double-blind placebo-controlled trial with open-label extension. British Journal of Psychiatry 200, 68-73.

Gordon J, Moore P (2005). ADHD among incarcerated youth: an investigation on the congruency with ADHD prevalence and correlates among the general population. American Journal of Criminal Justice 30, 87-97.

Gudjonsson G, Sigurdsson JF, Young S, Newton AK, Peersen M (2009). Attention deficit hyperactivity disorder: how do ADHD symptoms relate to personality among prisoners. Personality and Individual Differences 47, 64-68.

Gudjonsson GH, Sigurdsson JF, Adalsteinsson TF, Young S (2012). The relationship between ADHD symptoms, mood instability, and self-reported offending. Journal of Attention Disorders 17, 339-346.

Jensen EL, Gerber J, Mosher C (2004). Social consequences of the war on drugs: the legacy of failed policy. Criminal Justice Policy Review 15, 100-121.

Kessler RC, Adler L, Barkley R, Biederman J, Conners CK, Demler O, Faraone SV, Greenhill LL, Howes MJ, Secnik K, Spencer T, Ustun TB, Walters EE, Zaslavsky AM (2006). The prevalence and correlates of adult ADHD in the United States: results from the National Comorbidity Survey Replication. American Journal of Psychiatry 163, 716-723.

Konstenius M, Larsson H, Lundholm L, Philips B, Glind GV, Jayaram-Lindstrom N, Franck J (2012). An epidemiological study of ADHD, substance use, and comorbid problems in incarcerated women in Sweden. Journal of Attention Disorders. Published online: 13 July 2012. doi: $10.1177 / 1087054712451126$.

Langevin R (2003). A study of the psychosexual characteristics of sex killers: can we identify them before it is too late? International Journal of Offender Therapy and Comparative Criminology 47, 366-382.

Langley K, Fowler T, Ford T, Thapar AK, van den Bree M, Harold G, Owen MJ, O'Donovan MC, Thapar A (2010). Adolescent clinical outcomes for young people with attention-deficit hyperactivity disorder. British Journal of Psychiatry 196, 235-240.

Liberati A, Altman DG, Tetzlaff J, Mulrow C, Gotzsche PC, Ioannidis JP, Clarke M, Devereaux PJ, Kleijnen J, Moher D (2009). The PRISMA statement for reporting systematic reviews and meta-analyses of studies that evaluate health care interventions: explanation and elaboration. PLoS Medicine 6, e1000100.

Lichtenstein P, Halldner L, Zetterqvist J, Sjolander A, Serlachius E, Fazel S, Langstrom N, Larsson H (2012). Medication for attention deficit-hyperactivity disorder and criminality. New England Journal of Medicine 367, 2006-2014.
Lindsay WR, Carson D, Holland A, Michie AM, Taylor JL, Bambrick M, O'Brien G, Wheeler JR, Steptoe L (2012). A comparison of sex offenders and other types of offenders referred to intellectual disability forensic services. Psychiatry, Psychology and Law 19, 566-576.

McCarthy S, Wilton L, Murray ML, Hodgkins P, Asherson P, Wong IC (2012). The epidemiology of pharmacologically treated attention deficit hyperactivity disorder (ADHD) in children, adolescents and adults in UK primary care. BMC Pediatrics 12, 78 .

Milin R, Halikas JA, Meller JE, Morse C (1991). Psychopathology among substance abusing juvenile offenders. Journal of the American Academy of Child and Adolescent Psychiatry 30, 569-574.

Montejano L, Sasane R, Hodgkins P, Russo L, Huse D (2011). Adult ADHD: prevalence of diagnosis in a US population with employer health insurance. Current Medical Research Opinion 27 (Suppl. 2), 5-11.

Polanczyk G, de Lima MS, Horta BL, Biederman J, Rohde LA (2007). The worldwide prevalence of ADHD: a systematic review and metaregression analysis. American Journal of Psychiatry 164, 942-948.

Ponde MP, Freire AC, Mendonca MS (2011). The prevalence of mental disorders in prisoners in the city of Salvador, Bahia, Brazil. Journal of Forensic Sciences 56, 679-682.

Rasmussen K, Almvik R, Levander S (2000). ADHD in prisoners: an unfavourable index of criminal careers and a forensic challenge. Nordic Journal of Psychiatry $\mathbf{5 4}$ (Suppl. 43), 47.

Rasmussen K, Almvik R, Levander S (2001). Attention deficit hyperactivity disorder, reading disability, and personality disorders in a prison population. Journal of the American Academy of Psychiatry and Law 29, 186-193.

Retz W, Rosler M (2009). The relation of ADHD and violent aggression: what can we learn from epidemiological and genetic studies? International Journal of Law and Psychiatry 32, 235-243.

Retz W, Rosler M (2010). Association of ADHD with reactive and proactive violent behavior in a forensic population. Attention Deficit Hyperactivity Disorder 2, 195-202.

Rose E, Bramham J, Young S, Paliokostas E, Xenitidis K (2009). Neuropsychological characteristics of adults with comorbid ADHD and borderline/mild intellectual disability. Research in Developmental Disabilities 30, 496-502.

Rosler M, Retz W, Yaqoobi K, Burg E, Retz-Junginger P (2009). Attention deficit/hyperactivity disorder in female offenders: prevalence, psychiatric comorbidity and psychosocial implications. European Archives of Psychiatry and Clinical Neuroscience 259, 98-105.

Sanz-Garcia O, Dueñas RM, Burges V, Muro A, Perez F (2010a). Comorbidity in patients with attention deficit hyperactivity disorder in psychiatric population in prison. European Neuropsychopharmacology 20 (Suppl. 3), S616.

Sanz-Garcia O, Dueñas RM, Domenech N, Ramón R, Muro A, Perez F (2010b). How do we treat patients with undiagnosed attention deficit hyperactivity disorder? European Neuropsychopharmacology 20 (Suppl. 3), S623.

Senior J, Birmingham L, Harty MA, Hassan L, Hayes AJ, Kendall K, King C, Lathlean J, Lowthian C, Mills A, 
Webb R, Thornicroft G, Shaw J (2012). Identification and management of prisoners with severe psychiatric illness by specialist mental health services. Psychological Medicine 43, 1511-1520.

Simon V, Czobor P, Balint S, Meszaros A, Bitter I (2009). Prevalence and correlates of adult attention-deficit hyperactivity disorder: meta-analysis. British Journal of Psychiatry 194, 204-211.

Tidefors I, Strand J (2012). Life history interviews with 11 boys diagnosed with attention-deficit/hyperactivity disorder who had sexually offended: a sad storyline. Journal of Trauma and Dissociation 13, 421-434.

van Houwelingen HC, Arends LR, Stijnen T (2002). Advanced methods in meta-analysis: multivariate approach and meta-regression. Statistics in Medicine 21, 589-624.

Vitelli R (1996). Prevalence of childhood conduct and attention-deficit hyperactivity disorders in adult maximum-security inmates. International Journal of Offender Therapy and Comparative Criminology 40, 263-271.

WHO (1992). The ICD-10 Classification of Mental and Behavioural Disorders: Clinical Descriptions and Diagnostic Guidelines. World Health Organization: Geneva.

Willcutt EG (2012). The prevalence of DSM-IV attention-deficit/hyperactivity disorder: a meta-analytic review. Neurotherapeutics 9, 490-499.

Young S, Chesney S, Sperlinger D, Misch P, Collins P (2009a). A qualitative study exploring the life-course experiences of young offenders with symptoms and signs of ADHD who were detained in a residential care setting. Criminal Behaviour and Mental Health 19, 54-63.
Young S, Gudjonsson G, Ball S, Lam J (2003). Attention deficit hyperactivity disorder (ADHD) in personality disordered offenders and the association with disruptive behavioural problems. Journal of Forensic Psychiatry and Psychology 14, 491-505.

Young S, Gudjonsson G, Misch P, Collins P, Carter P, Redfern J, Goodwin E (2010a). Prevalence of ADHD symptoms among youth in a secure facility: the consistency and accuracy of self- and informant-report ratings. Journal of Forensic Psychiatry and Psychology 21, 238-246.

Young S, Gudjonsson GH (2008). Growing out of ADHD: the relationship between functioning and symptoms. Journal of Attention Disorders 12, 162-169.

Young S, Gudjonsson GH, Wells J, Asherson P, Theobald D, Oliver B, Scott C, Mooney A (2009b). Attention deficit hyperactivity disorder and critical incidents in a Scottish prison population. Personality and Individuality Differences 46, 265-269.

Young S, Misch P, Collins P, Gudjonsson G (2011). Predictors of institutional behavioural disturbance and offending in the community among young offenders. Journal of Forensic Psychiatry and Psychology 22, 72-86.

Young S, Morris R, Toone B, Tyson C (2007). Planning ability in adults with attention-deficit/hyperactivity disorder. Neuropsychology 21, 581-589.

Young S, Wells J, Gudjonsson GH (2010b). Predictors of offending among prisoners: the role of attention deficit hyperactivity disorder (ADHD) and substance use. Journal of Psychopharmacology 25, 1524-1532. 